\title{
Protective Role of Royal Jelly Against Gamma Radiation Induced Oxidative Stress, Cardio-Toxicity and Organ Dysfunctions in Male Rats \\ Hazem, K.A. Sarhan and Lilian, N. Naoum \\ Medical and Radiation Research Dept., Nuclear Material Authority, Cairo, Egypt
}

\begin{abstract}
Background: Oxidative stress is known to be a key factor in several diseases and was reported as a result of radiation exposure in human and experimental animals. Royal jelly contains free amino acids, proteins, sugars, fatty acids, minerals, and vitamins, which are reported as a preventive treatment of a wide range of disorders.

Aim: The present study was designed to determine the possible protective effects of royal jelly against gamma $(\gamma-)$ radiation-induced oxidative stress in male rats.

Materials and Methods: Thirty two rats were divided into four groups $(n=8)$, control, treated (rats were administrated by RJ ( $250 \mathrm{mg} / \mathrm{kg} /$ day) by stomach tube for 15 days, irradiated (rats were exposed to (10 Gy) whole body gamma radiations as a fractionated dose (2Gy X 5 times), treated irradiated, (rats were administrated by RJ $(250 \mathrm{mg} / \mathrm{kg} /$ day $)$ by stomach tube for 15 days before exposure to whole body gamma irradiation (10 Gy) as a fractionated dose (2X5). Serum reduced glutathione (GSH) content, superoxide dismutase (SOD) activity and lipid peroxide [malondialdehyde (MDA)] levels were assessed as well as serum total cholesterol (TC), triglyceride (TG), High density lipoprotein-cholesterol (HDL-C), low density lipoprotein-cholesterol (LDL-C), creatinine kinase-MB (CK-MB) and cardiac troponin I (cTnI). Also, histopathologic and histochemical changes were assessed. Results: The results showed that, GSH content, SOD activity and HDL-C were highly significantly decreased, while there was marked highly significant increase in MDA, TC, TG, LDL-C, CK-MB and cTnI due to irradiation. Numerous histopathologic changes were detected in the heart tissue of rats of the irradiated group with altered cardiac muscle fibres of the radiation-exposed group. These changes manifested good amelioration in the exposed groups that supplemented with RJ (250 $\mathrm{mg} / \mathrm{kg} / \mathrm{day})$.
\end{abstract}

Conclusion: Royal jelly has a beneficial role in reducing oxidative stress and cardio-toxicity induced by radiation exposure.

Keywords: Royal jelly; $\gamma$-irradiation; Antioxidant; cardio-toxicity.

\section{INTRODUCTION}

Ionizing radiation (IR) has attracted a lot of attention due to its beneficial as well as possible harmful effects to human population. Most of the toxic effects of ionizing radiation are due to generation of reactive oxygen species (ROS) by radiolysis of water which triggers formation of several reactive intermediates (1). Therefore, to overcome this oxidant stress, the body is equipped with defense system, including enzymatic and nonenzymatic radical scavengers that can either directly detoxify ROS or indirectly regulate their levels ${ }^{(2)}$.

Over production of ROS leads to uncontrolled chain reactions and lipid peroxidation, resulting in various pathological conditions that may include some body organ ${ }^{(3)}$. Radiation exposure attenuates endogenous antioxidant enzymes, which are considered to function as a part of the first line defense mechanism to maintain redox balance and normal biochemical processes. Thus, supplementation of antioxidants to improve the efficacy of radiotherapy is a current proposed strategy as antioxidants are capable to scavenge free radicals from the radiolysis of water and to protect cells from damage ${ }^{(4)}$. Radio-protectors aim to control the initial damage induced in the biological system at the molecular level before other physiological or micro-anatomical changes occur. This hypothesis is based on the use of chemicals that prevent the development of radiation injury in exposed organisms by mitigation of radionuclide absorption through activation of the free radical scavenging system ${ }^{(5)}$. An ideal radioprotective agent should be active, rapidly absorbed and easily distributed in the body tissues. It must be without side effects or at least with minimal toxicity which gives insurance that no cumulative consequences could be expected from their repeated usage ${ }^{(6)}$.

Royal jelly (RJ) has received a particular attention because of studies that have reported that it is a highly efficient antioxidant and has free radical scavenging capacity ${ }^{(7)}$. $\mathrm{RJ}$ is a secretion produced by the hypopharyngeal and mandibular glands of worker honeybees (Apismellifera). It contains many important compounds with biological activity such as free amino acids, proteins, sugars, fatty acids, minerals, and vitamins ${ }^{(8)}$. So far, RJ has been demonstrated to possess several physiological activities in experimental animals, including vasodilative and hypotensive activities ${ }^{(9)}$, anti-inflammatory ${ }^{(10)}$ and antioxidant properties ${ }^{(8)}$. 
This study was designed to estimate the possible protective effects of RJ against oxidative stress induced by gamma irradiation in male albino rats by measuring certain biochemical parameters (malondialdehyde, glutathione, superoxide dismutase, Cholesterol, triacylglycerol, high density lipoprotein, low density lipoprotein, creatinine kinase-MB and cardiac troponin I. In addition, monitoring the histological changes in heart tissues.

\section{MATERIALS AND METHODS}

\section{Animals:}

Male Swiss Albino rats (135-150 g) were obtained from the Egyptian organization for biological product and vaccines (Giza, Egypt). Animals were kept under good ventilation and illumination condition and received standard diet and had free excess to water.

\section{Chemicals and drugs:}

RJ was obtained from Sigma Company (Cairo).

\section{Preparation of royal jelly:}

RJ was prepared for supplementation by dissolving $3500 \mathrm{mg}$ RJ (lyophilized) in $50 \mathrm{ml}$ distilled water at a concentration of $70 \mathrm{mg} / \mathrm{ml}$ just before experimental use. This suspension was given to rats by gavage and every rat received RJ in a concentration of $250 \mathrm{mg} / \mathrm{kg}$ body weight ${ }^{(11)}$.

\section{Radiation processing:}

It was performed by using gamma cell-40 (Cesium-137) located at the National Centre for Radiation Research and Technology (NCRRT), Cairo, Egypt. Animals were irradiated at a fractionated dose level of 2X5 (10 Gy) delivered at a dose rate of $0.46 \mathrm{~Gy} / \mathrm{min}$. at the time of experimentation.

\section{Experimental design:}

Thirty two rats were divided into four groups. Group I (control group): rats received orally an equivalent volume of distilled water. Group II (treated group): rats were administrated by RJ ( 250 $\mathrm{mg} / \mathrm{kg} /$ day) by stomach tube for 15 days. Group III (irradiated group): rats were exposed to $10 \mathrm{~Gy}$ whole body gamma radiations as a fractionated dose (2X5) and like control group received orally an equivalent volume of distilled water. Group IV (treated irradiated group): rats were administrated by $\mathrm{RJ}(250 \mathrm{mg} / \mathrm{kg} / \mathrm{day})$ by stomach tube for 15 days before exposure to whole body gamma irradiation of (10Gy) as a fractionated dose (2X5). Rats were sacrificed on the $7^{\text {th }}$ day post radiation exposure.

\section{Samples collection:}

After an overnight fasting, rats were anesthetized with ether and blood samples from each rat were collected by retro-orbital puncture using blood capillary tubes then rats were sacrificed. Serum was obtained immediately by centrifugation of blood samples at $3000 \mathrm{rpm}$ for $10 \mathrm{~min}$. Heart was directly separated after sacrificing, washed in ice-cold saline then homogenized in distilled water $(10 \%$ $\mathrm{W} / \mathrm{V})$ using homogenizer. The cell debris was removed by centrifugation at $3000 \mathrm{rpm}$ for $10 \mathrm{~min}$. The homogenates supernatant were subjected to biochemical analysis. Tissue specimens from heart were collected and fixed in $10 \%$ buffered formalin solution and fixed tissues were dehydrated, cleared and embedded in natural paraffin. Another sample of the animals' hearts were isolated and prepared for paraffin blocks. Section of 5-micron thickness were prepared and stained routinely with haematoxylin and eosin (12) and examined microscopically.

\section{Estimation of biochemical parameters:}

MDA level was estimated following the method reported by Buege and Aust ${ }^{(13)}$, GSH content and SOD activity were determined according to the method described by Baker et al. ${ }^{(14)}$ and Kakkar et al. ${ }^{(15)}$ respectively. Concentrations of serum total cholesterol (TC), triacylglycerol (TG), High density lipoprotein-cholesterol (HDL-C) and low density lipoprotein-cholesterol (LDL-C) were determined according to the methods described by Allain $\boldsymbol{e t}$ al. ${ }^{(16)}$, Bucolo and David ${ }^{(17)}$, Demacker et al. ${ }^{(18)}$ and Marchal (19) respectively. Serum levels of creatinine kinase-MB (CK-MB) and cardiac troponin I (cTnI) were performed by ELISA technique (Bio-Source International, Camarillo, CA, USA) according to the manufacturer's instructions.

\section{Histological and histochemical techniques:}

Cardiac muscle fibres were immediately excised and fixed in $10 \%$ neutral formalin. Paraffin sections $(5 \mu \mathrm{m}$ in thickness) were prepared for processing the histological and histochemical studies. For general histology, sections were stained with Harris' haematoxylin and eosin ${ }^{(\mathbf{1 2})}$.

\section{Ethical approval:}

This study was conducted in accordance with ethical procedures and policies approved by Animal Care and Use Committee of Nuclear Material Authority, Egypt.

\section{Statistical analysis}

Data were analyzed using one way analysis of variance (ANOVA). The results obtained were expressed as mean \pm standard deviation (SD) of the mean. Differences were considered significant at $p$ $<0.05^{(\mathbf{2 0})}$. 


\section{RESULTS}

Table (1) presented MDA level, GSH content and SOD activity of rats exposed to (10 Gy) fractionated doses of radiation with and without Royal Jelly administration.

Irradiated group recorded highly significant elevation ( $\mathrm{P}<0.001)$ in MDA level, as compared to the corresponding non-irradiated group. In addition, it is evident from table (1) that irradiation caused highly significant depletion in GSH content and SOD activity $(\mathrm{P}<0.001)$. Groups treated with royal jelly pre-irradiation turned the value of MDA levelto its normal value, also caused amelioration in GSH content and SOD activity.

Table (1): Effect of the royal jelly on the level of malondialdehyde and glutathione content and superoxide dismutase activity in the four groups

\begin{tabular}{|c|c|c|}
\hline $\begin{array}{l}\text { MDA } \\
(\mathrm{mol} / \mathrm{l})\end{array}$ & $\begin{array}{c}\text { GSH } \\
(\mathbf{m g} / \mathbf{d l})\end{array}$ & $\begin{array}{l}\text { SOD } \\
(\mathrm{g} / \mathrm{ml})\end{array}$ \\
\hline $\begin{array}{c}73.0 \pm 6.2 \\
-\end{array}$ & $\begin{array}{c}47.4 \pm 3.0 \\
-\end{array}$ & $\begin{array}{c}62.0 \pm 5.2 \\
\cdots\end{array}$ \\
\hline $\begin{array}{c}72.4 \pm 6.0 \\
(-0.8)\end{array}$ & $\begin{array}{c}48.2 \pm 3.5 \\
(+1.6)\end{array}$ & $\begin{array}{c}61.0 \pm 5.0 \\
(-1.6)\end{array}$ \\
\hline$* * *$ & $* * *$ & $* * *$ \\
\hline $\begin{array}{c}103.0 \pm 10.2 \\
(+41.0)\end{array}$ & $\begin{array}{c}29.4 \pm 2.0 \\
(-37.9)\end{array}$ & $\begin{array}{c}38.4 \pm 2.6 \\
(-38.0)\end{array}$ \\
\hline $\begin{array}{c}* * \\
90.0 \pm 7.4 \\
(+23.2)\end{array}$ & $\begin{array}{c}38.0 \pm 2.6 \\
(-19.8)\end{array}$ & $\begin{array}{c}50.8 \pm 3.8 \\
(-18.0)\end{array}$ \\
\hline
\end{tabular}

mean of 8 rats \pm SE.

Significant different from the corresponding control group at $\mathrm{P}<0.05^{*}, \mathrm{P}<0.01^{* *}$ and $\mathrm{P}<0.001 * * *$.

The data in table (2) revealed that whole body gamma irradiation resulted in significant increase in serum total cholesterol, tri-acylglycerol, and low density lipoprotein concentrations with concomitant decrease in high density lipoprotein concentration. Groups treated with royal jelly pre-irradiation resulted in sufficient amelioration in all investigated parameters.

Table (2): Effect of the royal jelly on the serum level of TC, TG, HDL and LDL in all groups

\begin{tabular}{|c|c|c|c|}
\hline $\begin{array}{c}\text { TC } \\
(\mathrm{mg} / \mathrm{dl})\end{array}$ & $\begin{array}{c}\text { TG } \\
(\mathrm{mg} / \mathrm{dl})\end{array}$ & $\begin{array}{c}\text { HDL } \\
(\mathrm{mg} / \mathrm{dl})\end{array}$ & $\begin{array}{c}\text { LDL } \\
(\mathrm{mg} / \mathrm{dl})\end{array}$ \\
\hline $\mathbf{9 1 . 8} \pm \mathbf{8 . 0}$ & $\mathbf{8 3 . 3} \pm \mathbf{7 . 6}$ & $\mathbf{4 5 . 7} \pm \mathbf{4 . 0}$ & $\mathbf{2 9 . 5} \pm \mathbf{2 . 4}$ \\
--- & --- & --- & --- \\
\hline $90.6 \pm 7.8$ & $\mathbf{8 3 . 0} \pm \mathbf{7 . 2}$ & $\mathbf{4 6 . 0} \pm 3.9$ & $\mathbf{2 8 . 6} \pm \mathbf{2 . 0}$ \\
$(-1.3)$ & $(-0.3)$ & $(+\mathbf{0 . 6 5})$ & $(-3.0)$ \\
\hline$* * *$ & $* * *$ & $* * *$ & $* * *$ \\
$141.7 \pm 12.4$ & $144.5 \pm 14.0$ & $28.0 \pm 2.3$ & $\mathbf{8 4 . 8} \pm 7.8$ \\
$(+54.4)$ & $(+73.4)$ & $(-38.7)$ & $(+187.6)$ \\
\hline & $*$ & & $* * *$ \\
$103.0 \pm 9.7$ & $101.2 \pm 9.8$ & $36.5 \pm 3.3$ & $46.2 \pm 4.4$ \\
$(+12.2)$ & $(+21.4)$ & $(-20.0)$ & $(+56.6)$ \\
\hline
\end{tabular}

Legends as in table (1).

Table (3) showed that whole body gamma irradiation resulted in significant depletion in both CK-MB and cTnI. Treated groups by royal jelly pre-irradiation turned the values of CK-MB and cTnI to their normal values.

Table (3): Effect of the royal jelly on the serum level of CK-MB and cTnl in all groups

\begin{tabular}{|c|c|}
\hline $\begin{array}{c}\text { CK-MB } \\
(\mathbf{n g} / \mathbf{m L})\end{array}$ & $\begin{array}{c}\text { CTnI } \\
(\mathrm{ng} / \mathrm{mL})\end{array}$ \\
\hline $3.2 \pm 0.22$ & $25.7 \pm 2.0$ \\
---- & --- \\
\hline $2.9 \pm 0.3$ & $24.5 \pm 2.1$ \\
$(-9.3)$ & $(-4.6)$ \\
\hline$* * *$ & $* * *$ \\
$\mathbf{5 . 0} \pm 0.45$ & $39.5 \pm 3.4$ \\
$(+\mathbf{5 6 . 2})$ & $(+53.6)$ \\
\hline$*$ & $*$ \\
$4.0 \pm 0.42$ & $31.3 \pm 2.9$ \\
$(+\mathbf{2 5 . 0})$ & $(+21.7)$ \\
\hline
\end{tabular}

Legends as in table (1).

In the present study, the data revealed significant increase in MDA, TC, TG, LDL-C, CK$\mathrm{MB}$ and cTnI meanwhile. While, there was significant decrease in reduced glutathione content, superoxide dismutase and HDL-C due to irradiation effect. These changes created a series of oxidative stress in the biological system leading to propagation of superoxide radicals $\mathrm{H}_{2} \mathrm{O}_{2}$ and formation of hydroxyl radicals in the presence of metal ion catalysis.

\section{The histopatological study}

Several histopathologic changes were observed in heart tissue of the irradiated group (R). These changes included: Distorted cardiac muscle fibres with deeply stained nuclei (pyknotic) (P) and highly thickened and elongated arterial wall which contained haemolysed blood cells (Figure 3).

Blood and edema in the spaces of cardiac muscle in irradiated group (Figure 4). Irregular distribution of nuclei of myocytes of cardiac tissue appeared in the irradiated $+\mathrm{RJ}$ rat group (Figure 5). Somewhat normal appearance of cardiac muscle fibres was realized due to administration of RJ to the radiation-exposed group (Figure 6). 


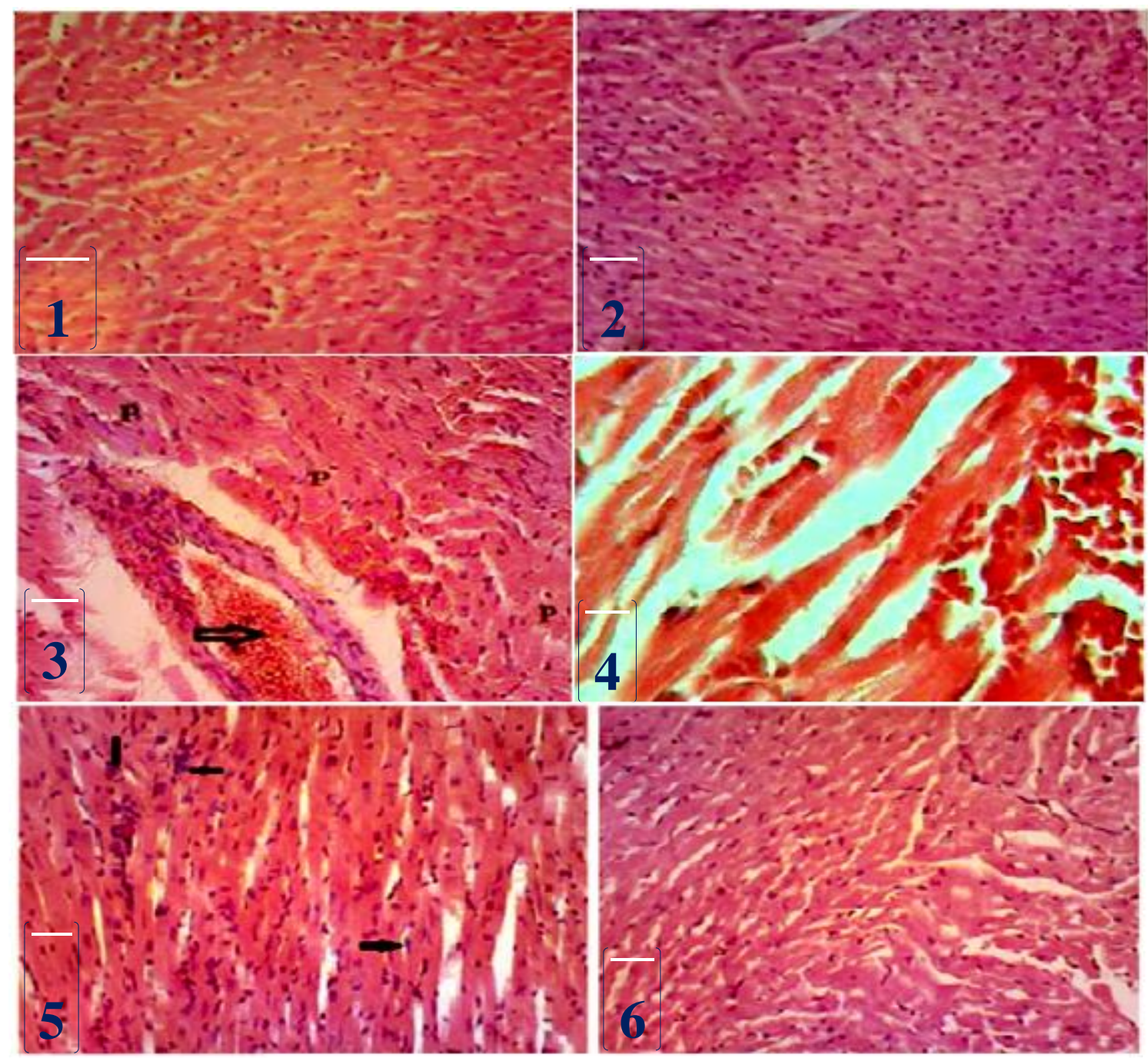

Figs. (1-6): Photomicrographs showing heart tissue of the control and treated groups (H \& Ex200). 1-Showing well developed cardiac muscle fibres of the control group. 2-Showing well developed and preserved cardiac muscle fibres of the royal jelly group. 3 -Showing distorted cardiac muscle fibres of a rat of the irradiated group (R) with deeply stained nuclei (pyknotic) (P) and highly thickened and elongated arterial wall, which contains haemolysed blood cells $(\Rightarrow)$. 4 - Showing blood and edema in the spaces of heart muscular (H \& E X400). 5-Showing somewhat normal appearance of the cardiac tissue, but nuclei of some myocyte are hypertrophied with irregular distribution of irradiated + RJ rat group $(\rightarrow)$ 6-Showing somewhat normal appearance of cardiac muscle fibres of irradiated $+\mathrm{RJ}$ rat group. 


\section{DISCUSSION}

Exposure to ionizing radiation is known to induce oxidative stress, which results in modification of DNA, proteins, lipids and small cellular molecules by reactive oxygen species (ROS), which plays a role in a wide range of common diseases and age-related degenerative conditions ${ }^{(21)}$. Tissue damages results from the energy transfer causing excitation, ionization or formation of free radicals in molecules of the encountered tissues ${ }^{(22)}$.

In the present study, histopathology of heart tissue from G 3 showed intramuscular edema. Cell membranes are rich sources of polyunsaturated fatty acids (PUFA) and incorporation of PUFA in membrane phospholipids influences membrane stabilization by modulating the fluidity of myocardial membrane ${ }^{(23)}$. However, it is also important to note that the presence of highly unsaturated PUFA makes the myocardial membrane easily susceptible to oxyradical induced necrotic damage resulting in increased release of diagnostic markers into the blood as observed in the present study. The presence of PUFA in cell membrane plays a major role in inhibition of cell volume reduction by modulating the elasticity of plasma membrane ${ }^{(24)}$. Cell volume affects the most basic processes of cell function and as such exerts an important role in the onset severity and outcome of myocardial infarction.

Evidence showed that hyperlipidemia and oxidative stress increases the risk of heart diseases, similarly the chronic overproduction of ROS leads to increased oxidation of LDL-C promoting the formation of plaque on cardiovascular vessels causing arteriosclerosis which increases the risk of stroke and heart failure ${ }^{(25)}$. The subsequent structural and ultrastructural damage may lead to cardiovascular complications and cardiac related death. Our data showed that whole body gamma exposure of rats by a fractionated dose of (2 X5Gy) resulted in hyperlipidaemia manifested by significant increase in the levels of serum TC, TG and LDL-C associated with significant decrease in HDL-C. A good correlation was established between elevation of LDL$\mathrm{C}$ and the decrease in HDL-C leading to high risk of the exposed animals to radiation damage. LDL-C could be oxidized in essence becoming a free radical itself (oxysterol). These results agree with the previous finding of Burcham et al. (26). Yokoyama et al. (27) explained that the increase in serum cholesterol level could be due to the decrease in lecithin cholesterol acyltransferase leading to a decrease in cholesterol esterification. Also, the increase in TG level of irradiated rats may be related to inhibition of lipoprotein lipase activity in adipose tissue between 24 and $48 \mathrm{~h}$ post-irradiation. Radiation exposure imposes an increased requirement for fat, which could result in mobilization of peripheral fat exiting tissue and its transportation by the blood.
In the present study, exposure to ionizing radiation caused highly significant increase in CK-MB andcTnI which agrees with Gharib ${ }^{(28)}$ who reported that gamma irradiation showed a significant increase in the level of serum enzyme CK-MP and cTnI due to the damage in the heart. The mechanism of radiationinduced cardio-toxicity has been reported to be through formation of superoxide anions and their derivatives, particularly highly reactive and damaging hydroxyl radicals, which induces peroxidation of cell membrane lipid (29). The cardiotoxicity occurs following exposure of rats to gamma radiation was significantly ameliorated by RJ treatment. It has been shown that chronic intake of RJ enhanced super-oxide dismutase activity in heart tissue which offers protection against oxidative stress associated with ischemic reperfusion injury (30). Moreover, all biochemical parameters were significantly attenuated to normal levels.

\section{The histopathologic and histochemical} changes in the heart tissue:

In the present study, photomicrographs showed distorted cardiac muscle fibres of the irradiated rats with deeply stained nuclei (pyknotic) and highly thickened and elongated arterial wall, which contained haemolysed RBCs in the radiation-exposed rat group. The present results come in agreement with the work of Khaki and Khaki ${ }^{(31)}$ who demonstrated that heart ventricular sections from rat group that exposed to radiation showed increased dark brown stained muscle fiber nuclei. Also, with the work done by Mohamed and Emam (32) who showed highly widened endomysium and degenerated muscle fibres with loss of striations with bizarre distribution of nuclei in heart of irradiated rats that exposed to 2 Gy gamma rays.

Damaged cardiac tissue observed in the present study may be due to increased lipid peroxidation (MDA) and decreased GSH and SOD levels. In this respect El-Habit et al. ${ }^{(33)}$ reported that the histological damage might result from an increase in the process of lipid peroxidation and a decrease in the activity of antioxidant enzymes with the consequent damage of cellular membranes.

\section{CONCLUSION}

Royal jelly has a beneficial role in reducing oxidative stress and cardio-toxicity induced by radiation exposure.

\section{REFERENCES}

1. Adaramoye O, Okiti O, Farombi E (2011): Dried fruit extract from Xylopiaaethiopica (Annonaceae) protects Wistar albino rats from adverse effects of whole body radiation. Exp Toxicol Pathol., 63: 635-39.

2. Sandeep D, Nair C (2012): Protection from lethal and sub-lethal whole body exposures of mice to $\gamma$-radiation 
by Acoruscalamus L.: studies on tissue antioxidant status and cellular DNA damage. Exp Toxicolpathol., 64: 5763.

3. Sener G, Kabasakal L, Atasoy B et al. (2006): Propylthiouracil-induced hypothyroidism protects ionizing radiation-induced multiple organ damage in rats. J Endocrinol., 189: 257-62.

4. Barker S, Weinfeld M, Zheng J et al. (2005): Identification of mammalian proteins cross-linked to DNA by ionizing radiation. J Biol Chem., 280: 338-42.

5. Cherupally K, Dillip K, Taisei $\mathbf{N}$ (2001): The potential radioprotective role of selenium on gamma irradiated rats' salivary glands. J Radiat Res., 42: 21-26.

6. Slyshenkov V, Omelyanchik S, Moiseenok A et al. (1999): Protection by pantothenol and beta-carotene against liver damage produced by low-dose gamma radiation. Acta Biochim Pol., 46: 239-45.

7. Silici S, Ekmekcioglu O, Kanbur M et al. (2010): The protective effect of royal jelly against cisplatin-induced renal oxidative stress in rats, World Journal of Urology, 29 (1): 127-132.

8. Nakajima Y, Tsuruma K, Shimazawa M et al. (2009): Comparison of bee products based on assays of antioxidant capacities. https://www.ncbi.nlm.nih.gov/pubmed/19243635

9. Takaki S, Hashimoto K, Yamamura M et al. (2009): Antihypertensive activities of royal jelly protein hydrolysate and its fractions in spontaneously hypertensive rats. Acta Medica Okayama, 63 (1): 57-64.

10. Kohno K, Okamoto I, Sano O et al. (2004): Royal jelly inhibits the production of pro- inflammatory cytokines by activated macrophages. Bioscience, Biotechnology and Biochemistry, 68 (1): 138-145.

11.Oka H, Emori Y, Kobayashi $N$ et al. (2001): Suppression of allergic reactions by royal jelly in association with the restoration of macrophage function and the improvement of Th1/Th2 cell responses. International Immuno-Pharmacology, 1 (3): 521-532.

12.Bancroft J, Stevens A (1996): Theory and Practice of Histological Techniques. 4th ed. Edinburgh; Churchill Livingstone, Pp: 766.

13. Buege J, Aust S (1978): Microsomal lipid peroxidation. Methods in Enzymology, 52: 302-310.

14.Baker M, Cerniglia G, Zaman A (1990): Microtiter plate assay for the measurement of glutathione disulphate in large number of biological samples. Anal Biochem., 190: 360-365.

15. Kakkar P, Das B, Viswanathan $P$ (1984): A modified spectrophotometric assay of superoxide dismutase. Ind $\mathbf{J}$ Biochem Biophys., 21: 130-132.

16. Allain C, Poon L, Chan C et al. (1974): Enzymatic determination of total serum cholesterol. Clin Chem., 20 (4): 470-75.

17. Bucolo G, David H (1973): Quantitative determination of triglycerides by the use of enzymes. Clin Chem., 19: 476-482.
18. Demacker P, Janssen H, Hijmans A et al. (1980): Measurement of high-density lipoprotein cholesterol in serum: Comparison of six isolation methods combined with enzymic cholesterol analysis. Clin Chem., 26 (13): 1780-83.

19. Marchal W (1992): Clinical Chemistry, $2^{\text {nd }}$ Gower Medical Publishing, U.K., Pp: 222.

20.George W, William G (1980): Statistical Methods, Seventh Edition, Pp: 217.

21. Borek C (1997): Antioxidants and cancer. Sci Med., 4: 51- 62.

22.Astdr G (1999): Agency for Toxic Substance and Disease Registry. U.S. Department of Health and Human Services. Public Health Service. https://www.atsdr.cdc.gov/toxprofiles/tp.asp?id=96\&tid $=22$

23. Rezk R, Yacoub S, Abd El Aziz N (2009): Squalene Modulates Radiation-induced structural, ultra-structural and biochemical changes in cardiac muscles of male albino rats. Isotope \& Rad Res., 41: 1705-7.

24.Sanchez-Olea R, Morales-Mulia M, Moran J et al. (1995): Inhibition by polyunsaturated fatty acids of cell volume regulation and osmolyte fluxes in astrocytes. Am J Physiol., 269: 96-98.

25.Madamanchi N, Runge M (2007): Mitochondrial dysfunction in atherosclerosis. Circ Res., 100: 460-5.

26. Burcham P, Kaminskas L, Fontaine F et al. (2002): Aldehyde-sequestering drugs: tools for studying protein damage by lipid peroxidation products. Toxicology, 229: 181-182.

27. Yokoyama K, Tani S, Matsuo $\mathrm{R}$ et al. (2018): Association of lecithin-cholesterol acyltransferase activity and low-density lipoprotein heterogeneity with atherosclerotic cardiovascular disease risk: a longitudinal pilot study. BMC Cardiovasc Disord., 18(1):224.

28. Gharib OA (2007): Does kombucha tea reduce the damage-induced by radiation exposure? Egypt J Rad Sci Applic., 20: 141-6.

29.Hemnani T, Parihar M (1998): Reactive oxygen species and oxidative DNA damage. Ind J Physiol Pharmacol., 42: 440-443.

30. Khaled S, Mohamed B, Mahmoud S et al. (2011): Royal Jelly Modulates Oxidative Stress and Tissue Injury in Gamma Irradiated Male Wister Albino rats. North American Journal of Medical Sciences, 3 (6): 2682776.

31. Khaki AA, Khaki A (2012): Protective effects of basil on cardiac cells apoptosis after chronic exposure to electromagnetic field (EMF) in rats by TUNEL assay. Internat J of Biosci., 2 (12): 13-20.

32. Mohamed N, Emam M (2013): The possible protective role ofbone marrow transplantation against alternations induced by gamma radiations on heart of pregnant albino rats and their fetuses. J Biol Life Sci., 4 (1): 1-8.

El-Habit O, SaadaH, Azab K et al. (2000): The modifying effect of beta carotene on gamma radiation-induced elevation of oxidative reactions and genotoxicity in male rats. Mutat Res., 466 (2): 179-86. 